\title{
Study on a Mid-Temperature Trough Solar Collector with Multisurface Concentration
}

\author{
Zhengliang Li, ${ }^{1}$ Mingxian Chen, ${ }^{1}$ Husheng Meng, ${ }^{1}$ Zehui Chang, ${ }^{2}$ and Hongfei Zheng ${ }^{3}$ \\ ${ }^{1}$ College of Physics and Electronic Engineering, Guangxi Teachers Education University, Nanning 530023, China \\ ${ }^{2}$ College of Energy and Power Engineering, Inner Mongolia University of Technology, Hohhot 010051, China \\ ${ }^{3}$ School of Mechanical and Vehicular Engineering, Beijing Institute of Technology, Beijing 100081, China \\ Correspondence should be addressed to Hongfei Zheng; hongfeizh@bit.edu.cn
}

Received 7 January 2015; Revised 25 April 2015; Accepted 28 April 2015

Academic Editor: Elias Stathatos

Copyright (C) 2015 Zhengliang Li et al. This is an open access article distributed under the Creative Commons Attribution License, which permits unrestricted use, distribution, and reproduction in any medium, provided the original work is properly cited.

A new trough solar concentrator which is composed of multiple reflection surfaces is developed in this paper. The concentrator was analyzed firstly by using optical software. The variation curves of the collecting efficiency affected by tracking error and the deviation angle were given out. It is found that the deviation tolerance for the collector tracking system is about 8 degrees when the receiver is a $90 \mathrm{~mm}$ flat. The trough solar concentrators were tested under real weather conditions. The experiment results indicate that, the new solar concentrator was validated to have relative good collecting efficiency, which can be more than 45 percent when it operated in more $145^{\circ} \mathrm{C}$. It also has the characteristics of rdust, wind, and snow resistance and low tracking precision requirements.

\section{Introduction}

Traditional solar parabolic trough concentrator is one of the most widely used and well developed solar heat collector technologies. It has been applied successfully in many large thermal power plants [1-4]. It can reach more than $400^{\circ} \mathrm{C}$ when controlled by the precise solar tracking systems. However, it has the following disadvantages [5, 6]: (1) the requirement is very high not only for the sun-tracking system but also for the paraboloide. If the reflected light cannot be reached by the receiver, the light would be invalid. It is difficult to achieve a satisfied result for a low cost solar heating system. (2) This facility is easily affected by wind, snow, and dust. And these would reduce the efficiency of system. (3) High temperature solar receiver is installed on the top of the reflecting surface, so the heat losses to the environment are very high by radiation heat transfer. Both the installation and the insulation for the receiver are difficult.

Aiming at overcoming the shortage of the traditional groove parabolic concentrating collectors in recent years, many researchers have studied and designed various kinds of collectors. For example, Richter [7] introduced a new kind of solar concentrator which consisted of double parabolic troughs, which can improve light-gathering efficiency and concentrating ratio in winter. Tao et al. [8] studied an image by the focus of overlapping combination surface concentrated groove collector, which was investigated and experimentally tested. It proves that the groove type concentrator can greatly reduce the requirement of tracking precision. Riffat and Mayere [9] introduced a new type V-shaped groove concentrator for desalination. The collector using a heat conduction oil coil heater can increase the temperature of water to more than 100-degree centigrade. The total water production efficiency can be 38 percent. Anderson (2013) [10] studied a trapezoidal groove type solar collector and studied the process of natural convection heat transfer. Tsai and Lin [11] studied a zoom groove parabolic concentrator, in the zoom range, it can collect more than $90 \%$ of the light. The researches of various new type solar collector mentioned above provide the methods to reduce the accuracy requirement for tracking device and increase the ability to resist environment interference.

Based on the previous research results, a new type of the combined surface parabolic concentrator is introduced in this paper, in which a transparent cover is installed in its opening. Its reflection surface is composed of multiple curved surfaces, which allows the solar receiver to be synchronously heated at the upper and lower surfaces. It is helpful to improve 


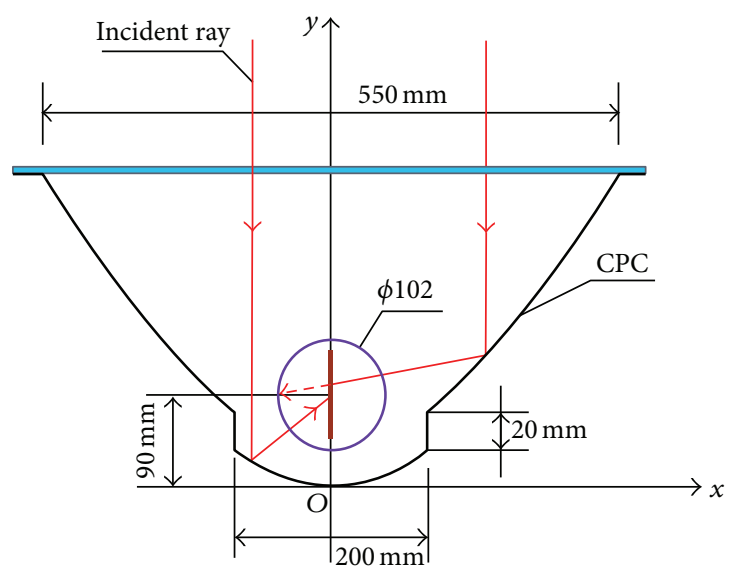

FIGURE 1: Multisurface groove concentrator focusing principle and geometry dimension.
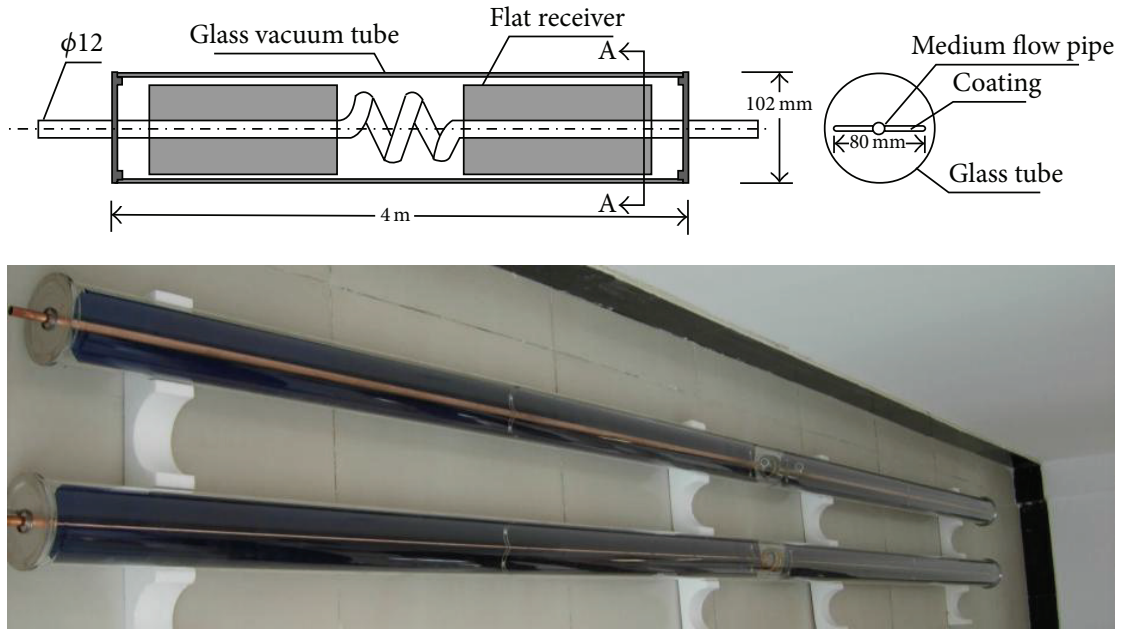

FIGURE 2: Structure and photo of the evacuated-tube finned plate solar receiver.

the efficiency of the receiver. Because the focus line of the concentrator is at the lower part of the concentrator, it offers convenience for installation and thermal insulation of the receiver [12]. At the same time, it reduces the demand for solar tracking precision. The system also improves the reflective surface dust resistance and the ability to resist wind and snow. It also greatly reduces the heat losses of the receiver and improves the efficiency of the system. At the same time, the system is easily installed and the receiver is stationary.

\section{Operating Principle and Structure of the System}

The focusing principle and geometry relationship of the new collector are shown in the Figure 1; the cross section is mainly composed of a CPC concentrator, a low parabolic reflector with two straight edges, and a bottom. As shown in Figure 1, the focus of the right parabola of the CPC concentrator is on the left side of the glass tube. Also the focus of the left parabola of the CPC concentrator is on the right side of the glass tube. The focus of the parabola at the bottom of the concentrator is exactly on the center of the receiver. Two straight edged mirrors will have the effect of further concentrating when the sun is not normal incidence.

The function of CPC is

$$
y=-4.67+0.28 x+0.003 x^{2}
$$

and the parabolic function at the bottom part of the CPC is

$$
y=\frac{x^{2}}{300} .
$$

The lowest point of the curve expressed by the parabolic function at the bottom part of the CPC is the coordinate origin shown in Figure 1. The dimension of the CPC is shown in Figure 1 too. The width of the entrance of the concentrator is $550 \mathrm{~mm}$, the width of low parabola is $200 \mathrm{~mm}$, and the length of the straight edges is $20 \mathrm{~mm}$. The distance from the receiver center to the origin (i.e., the lowest point) is $y=$ $90 \mathrm{~mm}$. The receiver is an evacuated tubular solar receiver with finned plate. The internal structure and the photo are shown in Figure 2. The length of one vacuum tube is $4 \mathrm{~m}$. 

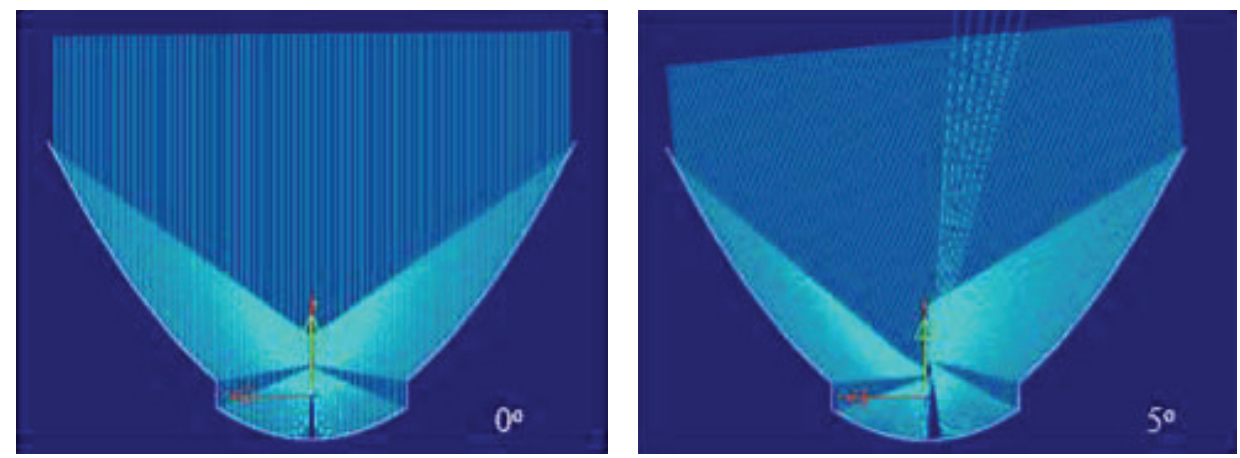

FIGURE 3: Light tracing analysis of the concentrator.

\section{Analysis and Optical Simulation on the System}

Most of the concentrated solar collectors need to track the sun. The cost of a tracking facility is determined by the accuracy requirement of the tracking facility. The analysis and optical simulation were carried out on the system to evaluate the focusing performance of this system. According to the geometrical parameters and curve equation, a 3D model of the system was established in Pro/ENGINEER software, which was saved as IGES format and then inputted into an optical simulation software called LightTools. In LightTools simulation, the all reflection surfaces are defined to be aluminum and its reflectance is assumed to be $100 \%$. The beam of rays includes $1 \times 500$ parallel rays. The incident angle was changed to investigate how many light rays can reach the receiver. The simulation results are shown Figure 3 when the incident angles of the light are $0^{\circ}$ and $5^{\circ}$. As shown in Figure 3, when the incident angles are in the range of $\pm 5^{\circ}$, more than $97 \%$ lights can reach the receiver with width of $90 \mathrm{~mm}$ which is the same as the width of evacuated tubular receiver used in the experiment.

The efficiency curve of the concentrator is shown in Figure 4 . It is found from Figure 4 that about $84 \%$ of the light can reach the receiver even if the deviation of the tracking angle is $8^{\circ}$. It means that the requirement for the suntracking device for the multisurface concentrator is very low. Therefore the sun tracker simply controlled by a common stepper motor, which is cheaper compared with other high performance sun trackers, can be used for the concentration system.

Additionally the receiver usually moves together with the concentrator to track the sun in a traditional solar parabolic trough concentrator. The phenomena of oil leaking often happen and it is difficult to insulate the whole receiver. Hence the receiver can be fixed and only the concentrator tracks the sun in this system. This will increase the reliability of the system. But it will bring a disadvantage. Namely, the receiver plate might not coincide with the symmetry axis of the concentrator and a certain angle appears which will result in the losses of lights. This phenomenon does not happen in the tubular receiver. However the following calculations show that the losses of light are acceptable when the angle is not

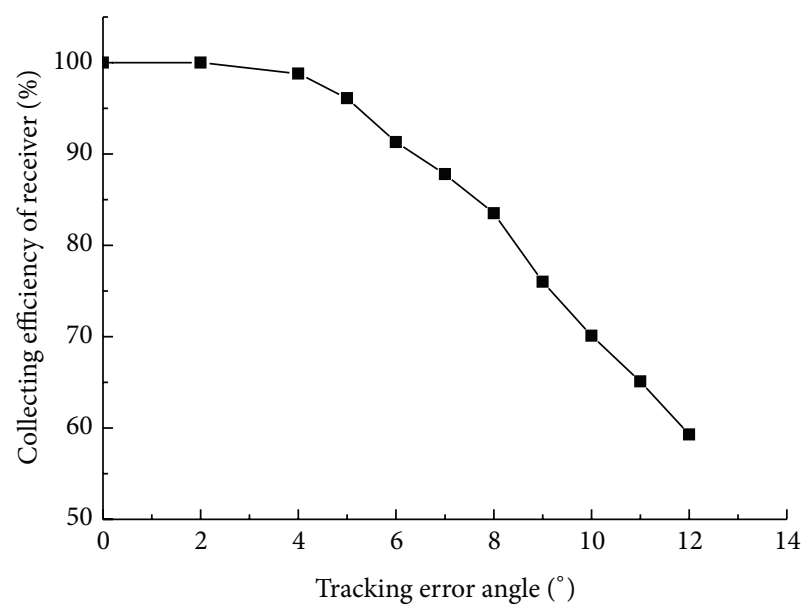

FIGURE 4: The efficiencies of concentrator change with the deviation of the tracking angles.

large. Comparing to the tubular receiver, the receiver with plate fin is cheaper.

Figure 5 shows the results when the deviation angle between the receiver plate and the symmetry axis of the concentrator which is the normal line of entrance plane of the concentrator is between $10^{\circ}$ and $25^{\circ}$, respectively. The influences of the deviation angle on the concentrator efficiency are shown in Figure 6. From Figures 5 and 6, it can be seen that the light loss is only $5 \%$ even though the deviation angle between the receiver plate and the symmetry axis is $25^{\circ}$. This is completely acceptable. It indicates that, for north latitude being more than $25^{\circ}$ regions, if the concentration system is placed in east-west direction and faces to south, the concentration system can operate throughout the whole year with high efficiency because the installed angle (about $25^{\circ}$ ) of the system and receiving angle $\left(2 \times 25^{\circ}\right)$ together are basically covering the sun altitude angle which is always less than $90^{\circ}$ in a year.

\section{Experimental System}

Based on the principle of concentration system and the investigation on the trough collector, one experimental setup was 

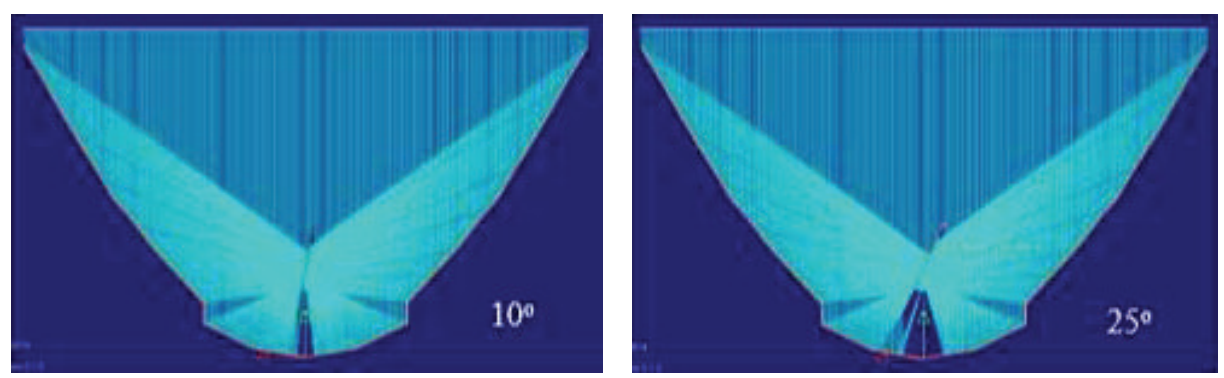

FIGURE 5: Optical simulation results when receiving plate is not coincidence with the symmetry axis of concentrator.

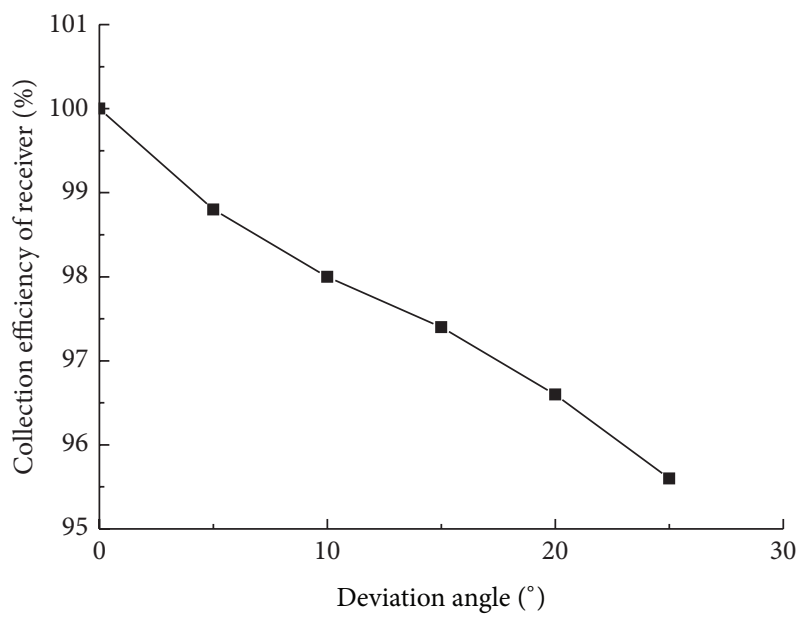

FIGURE 6: The influences of the angle between receiver plate and concentrator symmetry axis on the concentrator efficiencies.

developed and is shown in Figure 7. This system consists of trough solar collector, finned tube, oil storage tank, working fluid, and circulation pumps; the internal working fluid is ordinary thermal oil with maximum using temperature of $350^{\circ} \mathrm{C}$, density of $875 \mathrm{~kg} / \mathrm{m}^{3}$ in $16^{\circ} \mathrm{C}$, and specific heat capacity of $2.1 \mathrm{~kJ} / \mathrm{kg} \cdot \mathrm{K}$ in $100^{\circ} \mathrm{C}$. The length of one tube is 4 meters. The reflectivity of the absorber is about $90 \%$ and the parabolic reflector is made of the high reflective aluminum plate which is shown in Figure 8. There are four sets of collectors in which two sets are series and the others are parallel. They are placed in the east-west direction. The absorber structure of the receiver is a finned plate coated with a selective absorbing coating. The outer tube of the receiver is a glass tube and is evacuated. Therefore the receiver has a very good thermal performance.

A single-axis solar tracking photovoltaic-driven system operates with one motor, which is powered by sunlight. One electronic measuring device in the tracking system can determine whether the receiver is in the right position on the basis of the symmetrical principle. If the receiver is not in the best position, the servomotor will receive a control signal and will move upwards the angle of tracking system until the receiver reaches the best position.

A mercury thermometer with a minimum scale division of $1^{\circ} \mathrm{C}$ was used to measure the ambient temperature. The detailed technical specifications of instruments used in experimental setup are presented in Table 1.
When the system is operating, the sunlight will be reflected to the tubular receiver by the reflector. The absorber will absorb the solar radiation and convert it into the heat. The heat will be transferred to the working fluid in the internal tube of the receiver. The working fluid is driven by a pump and the heat will be stored in the oil tank via circulation. All tubes are well insulated. The inlet and outlet temperatures of the solar collector as well as the temperature of heat storage are measured which are shown in Figure 7.

\section{Analysis of Testing Data}

5.1. Operating Temperature Test System. The experimental system was installed in Lianyungang City, Jiangsu Province (longitude $119^{\circ}$, latitude $34^{\circ}$ ). The ambient temperature is $23-27^{\circ} \mathrm{C}$; the mass of the oil in the heat storage tank is $50 \mathrm{~kg}$. The volumetric flow rate of the working fluid is about $5.5 \mathrm{~L} / \mathrm{min}$. The total aperture area of concentrator is about $8 \mathrm{~m}^{2}\left(8 \times 1.85 \times 0.55 \mathrm{~m}^{2}\right)$. Solar irradiance is provided by a nearby and self-built small weather station. The testing was carried out in May 21 and 23, 2014. The variation curves of solar irradiance and outlet temperature of solar collector in 5 mins gap with time are shown in Figure 9. The average value of solar radiation testing data is about $850 \mathrm{~W} / \mathrm{m}^{2}$. For controlling the oil temperature in the tank, some heat was sent to user to prevent the system working in too high temperature. As shown in Figure 9, it took about two hours to increase the outlet temperature of the solar collector from $60^{\circ} \mathrm{C}$ to $100^{\circ} \mathrm{C}$ in May 21 . At ten o'clock in the morning the outlet temperature reached $100^{\circ} \mathrm{C}$. In May 23, it remained above $100^{\circ} \mathrm{C}$ until four o'clock in the afternoon. The total period of time in which the outlet temperature was above $100^{\circ} \mathrm{C}$ is 6.5 hours. As a result, this system can provide midtemperature heat energy for users.

The variation of temperature difference between the outlet and inlet of solar collectors with time is shown in Figure 10. It is found that from 9:30 to 14:30, the temperature differences are kept above $15^{\circ} \mathrm{C}$ in May 23, particularly in the time range of 11:00 and 13:00, the temperature differences are close to $20^{\circ} \mathrm{C}$. It indicates that the system still has relative high efficiency even if it is working at more than $100^{\circ} \mathrm{C}$.

5.2. Collecting Efficiency of the System. Collector efficiency is an important parameter to reflect the performance of the collectors. The average efficiency of five minutes under operating conditions is calculated. The heat obtained by 
TABLE 1: Technical specifications of instruments used in experimental setup.

\begin{tabular}{lcc}
\hline Instrumentation & Range & Accuracy \\
\hline Average wind speed measurement chip/Kanomax-KA22 & $0.1-50 \mathrm{~m} / \mathrm{s}$ & $\pm 0.2 \%$ \\
Liquid turbine flow meter/LWYC-15 & $0-20 \mathrm{~L} / \mathrm{min}$ & $\pm 0.5 \%$ \\
32-channel digital data-recording/JLS-XMT & $-200-600^{\circ} \mathrm{C}$ & $\pm 0.5 \%$ \\
Temperature measuring sensors/Pt100 & $-20-300^{\circ} \mathrm{C}$ & $\pm 0.1^{\circ} \mathrm{C}$ \\
High temperature oil circulation pump/120 W & $0-8 \mathrm{~L} / \mathrm{min}$ & \\
Tracking motor/25 W & & \\
\hline
\end{tabular}

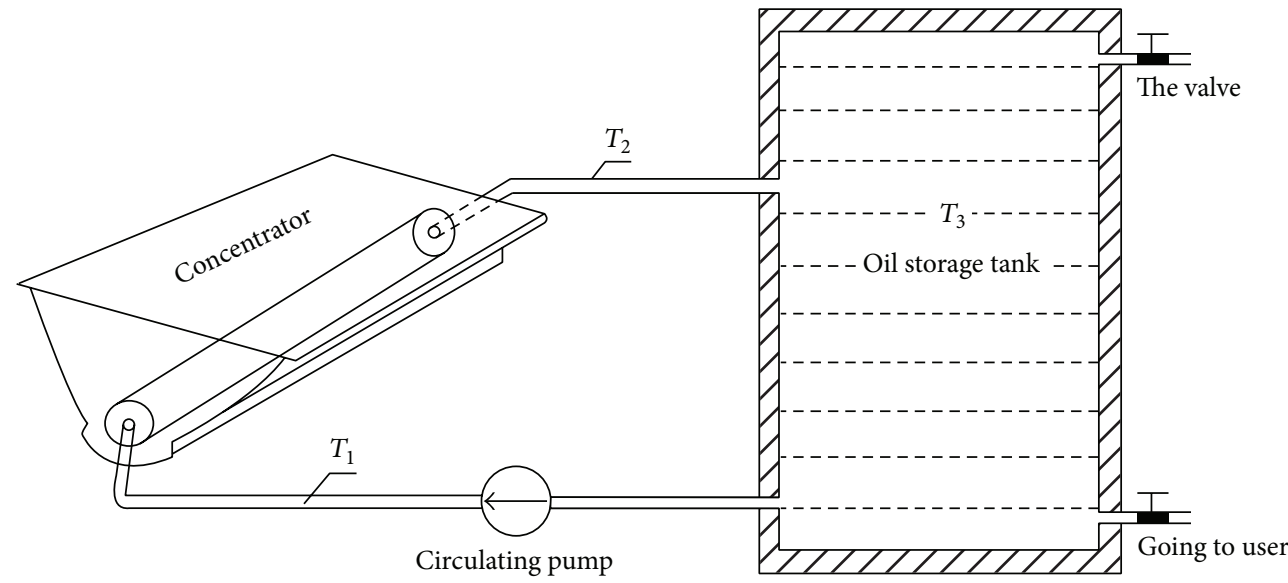

FIGURE 7: Experimental setup of the new trough solar collection system.

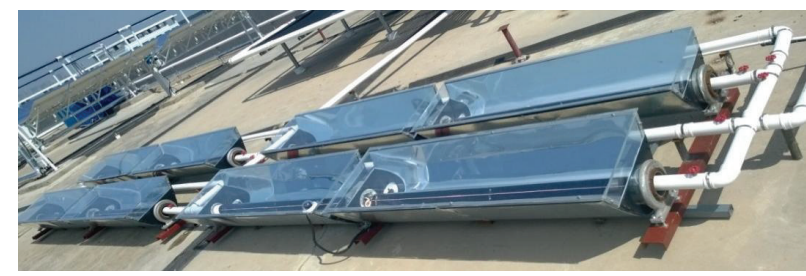

FIGURE 8: Experimental system photo.

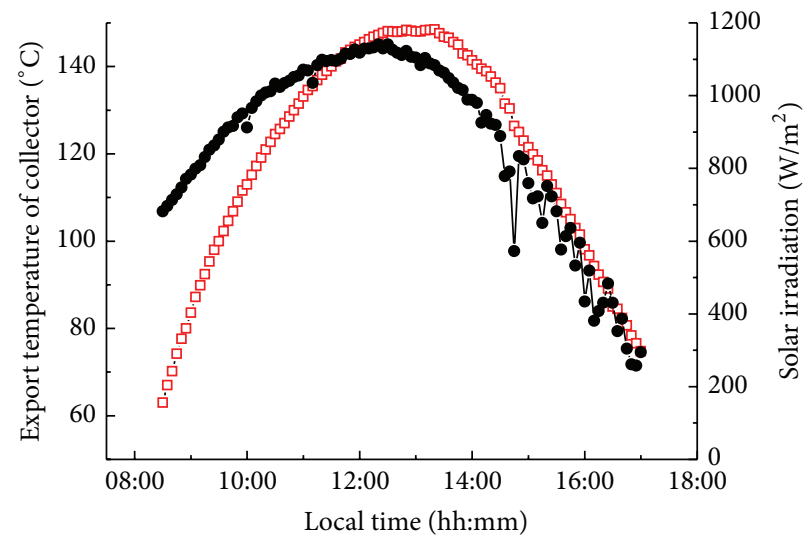

- Export temperature of collector $-\square-$ Solar irradiation

(a) On May 25, 2014

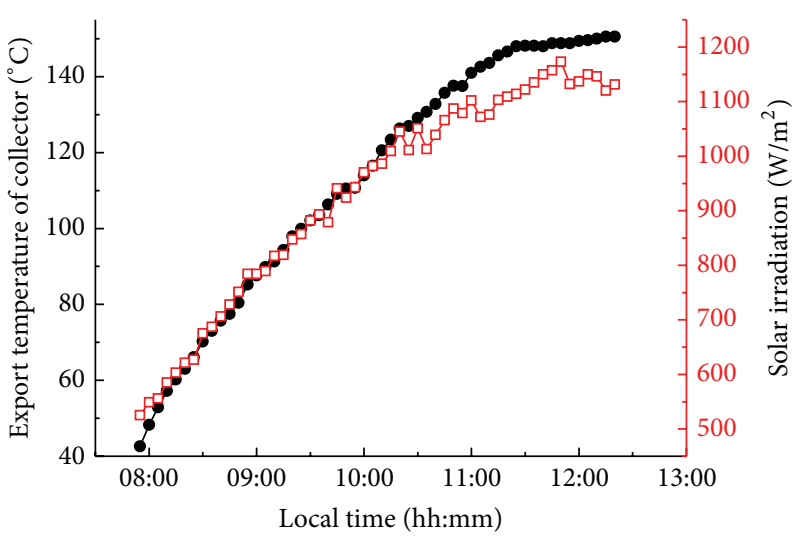

- Export temperature of collector $\neg-$ Solar irradiation

(b) On May 21, 2014

FIGURE 9: The variations of solar radiation and export temperature of solar collector with time. 


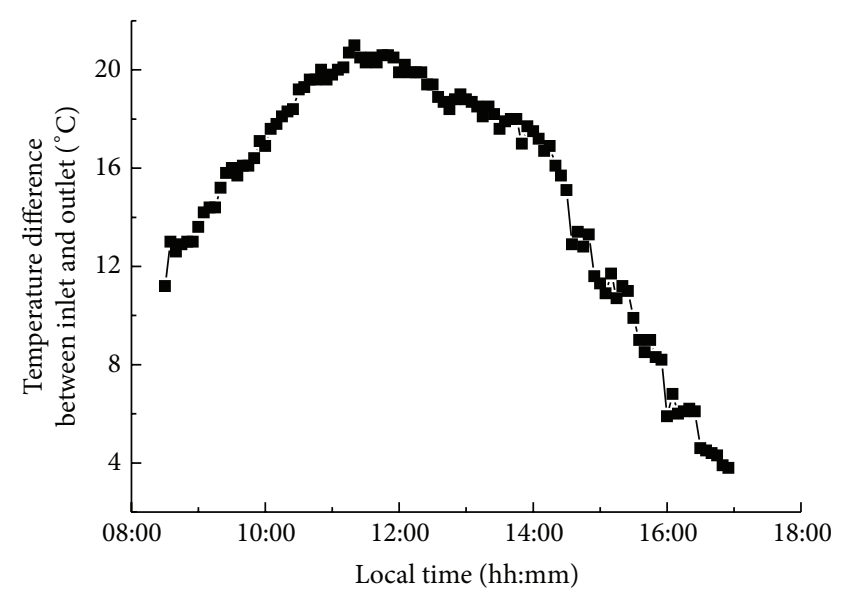

(a) On May 25, 2014

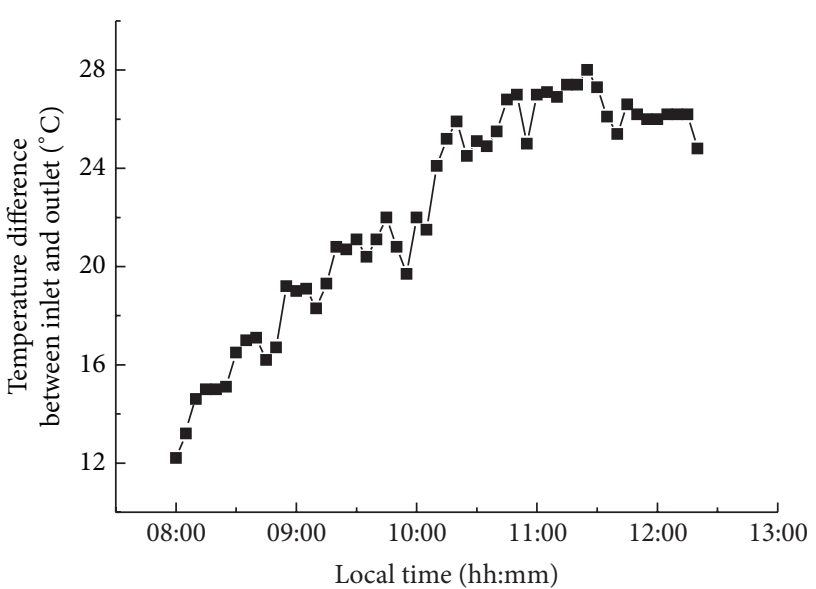

(b) On May 21, 2014

FIGURE 10: The variations of temperature difference between outlet and inlet of solar collector with time.

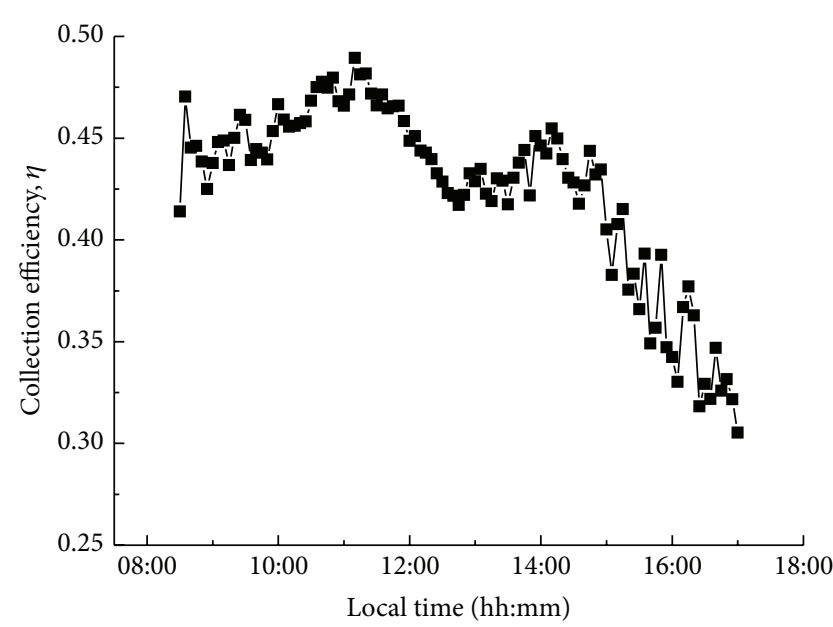

(a) On May 25, 2014

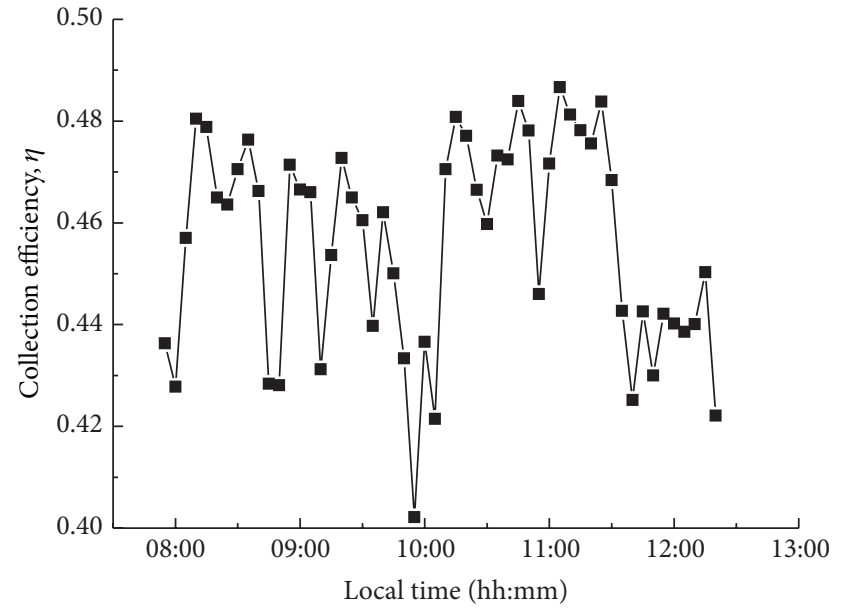

(b) On May 21, 2014

FIGURE 11: Variation of the average efficiency of concentrator with time.

the collectors from the solar radiation is determined by the temperature difference of the outlet and the inlet of the solar collector and the flow rate in the pipes. Collector efficiency is the ratio of the heat and the total solar radiation incident on the collectors. The calculation formula is as follows:

$$
\eta=\frac{c_{p} \cdot m_{f} \cdot \Delta T}{I \cdot A+P \cdot t},
$$

where $c_{p}, m_{f}, \Delta T, I$, and $A$ are specific heat capacity, mass flow rate of working fluid, temperature difference of the outlet and the inlet of the solar collectors, irradiance, and the total aperture area of collectors. $P$ is the power of the circulation pump; $t$ is the working time of the pump.

As shown in Figure 11 the average efficiency per five minutes under operating conditions can reach about 45 percent. During testing days, the collecting efficiency of the system can remain above $40 \%$ for more than 7 hours. These illustrate that the performances of the solar concentrator in the system are very good which reaches the traditional parabolic trough concentrator. The results also indicate that the system has more efficiency in the noon because the deviation angle is less during this period. The efficiency will decrease in the morning or afternoon with the deviation angle increasing and solar radiation becoming weak.

\section{Conclusions}

A multisurface trough concentrating solar collector is introduced and tested in laboratory. The optics simulation results indicate that its deviation tolerance is about 8 degrees for the collector tracking system for a $90 \mathrm{~mm}$ flat receiver. The experimental results show that the system can easily achieve high temperature above $100^{\circ} \mathrm{C}$ under operating conditions. This situation lasted about 6.5 hours. There are 7 hours of time in which the average efficiencies of five minutes are more than 40 percent. The temperature difference between input and output is often more than $10^{\circ} \mathrm{C}$ which shows that the heat 
performance of the concentrating solar collector is very good. It also has the advantages of wide receiving angle and good ability of dust, wind, and snow resistance. It means that the solar collector can be utilized in many applications of solar energy, such as desalination, space heating, air-conditioning, and hot water system. The commercial market is promising.

\section{Conflict of Interests}

The authors declare that there is no conflict of interests regarding the publication of this paper.

\section{Acknowledgments}

This research was supported by the Key Program in Guangxi Colleges and Universities (no. 2012ZD063) and the Science and Technology Program of Guangxi Colleges and Universities (no. 2013YB144). The authors would also like to thank the Natural Science Foundation of Inner Mongolia Autonomous Region, China (no. 2013MS0704).

\section{References}

[1] A. Thomas and H. M. Guven, "Parabolic trough concentratorsdesign, construction and evaluation," Energy Conversion and Management, vol. 34, no. 5, pp. 401-416, 1993.

[2] A. Fernández-García, E. Zarza, L. Valenzuela, and M. Pérez, "Parabolic-trough solar collectors and their applications," Renewable and Sustainable Energy Reviews, vol. 14, no. 7, pp. 1695-1721, 2010.

[3] M. Wirz, J. Petit, A. Haselbacher, and A. Steinfeld, "Potential improvements in the optical and thermal efficiencies of parabolic trough concentrators," Solar Energy, vol. 107, pp. 398414, 2014

[4] M. Khamooshi, H. Salati, F. Egelioglu, A. Hooshyar Faghiri, J. Tarabishi, and S. Babadi, "A review of solar photovoltaic concentrator," International Journal of Photoenergy, vol. 2014, Article ID 958521, 17 pages, 2014.

[5] W. Huang, P. Hu, and Z. Chen, "Performance simulation of a parabolic trough solar collector," Solar Energy, vol. 86, no. 2, pp. 746-755, 2012.

[6] A. V. Arasu and T. Sornakumar, "Design, manufacture and testing of fiberglass reinforced parabola trough for parabolic trough solar collectors," Solar Energy, vol. 81, no. 10, pp. 12731279, 2007.

[7] J. L. Richter, "Optics of a two-trough solar concentrator," Solar Energy, vol. 56, no. 2, pp. 191-198, 1996.

[8] T. Tao, Z. Hongfei, H. Kaiyan, and A. Mayere, "A new trough solar concentrator and its performance analysis," Solar Energy, vol. 85, no. 1, pp. 198-207, 2011.

[9] S. Riffat and A. Mayere, "Performance evaluation of v-trough solar concentrator for water desalination applications," Applied Thermal Engineering, vol. 50, no. 1, pp. 234-244, 2013.

[10] T. N. Anderson, "Natural convection heat transfer in V-trough solar concentrators," Solar Energy, vol. 95, pp. 224-228, 2013.

[11] C.-Y. Tsai and P. D. Lin, "Optimized variable-focus-parabolictrough reflector for solar thermal concentrator system," Solar Energy, vol. 86, no. 5, pp. 1164-1172, 2012.
[12] H. Kaiyan, Z. Hongfei, and T. Tao, "A novel multiple curved surfaces compound concentrator," Solar Energy, vol. 85, no. 3, pp. 523-529, 2011. 

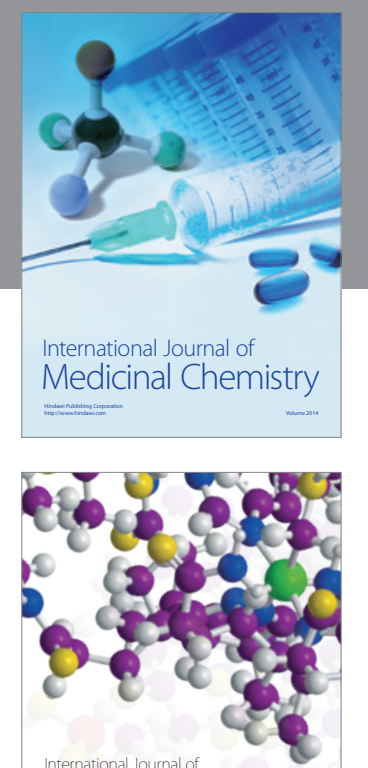

\section{Carbohydrate} Chemistry

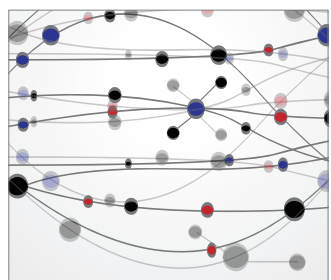

The Scientific World Journal
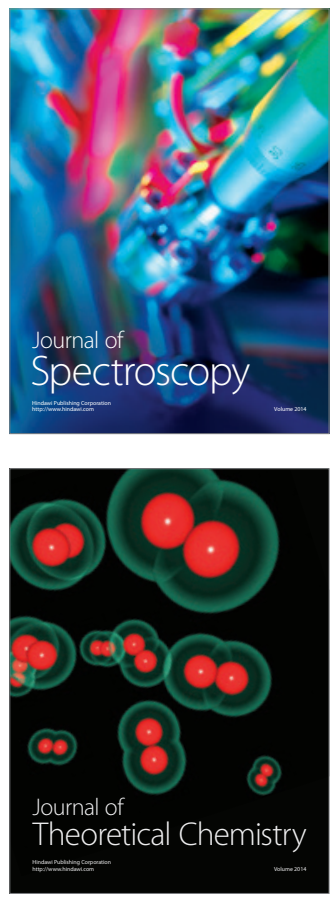
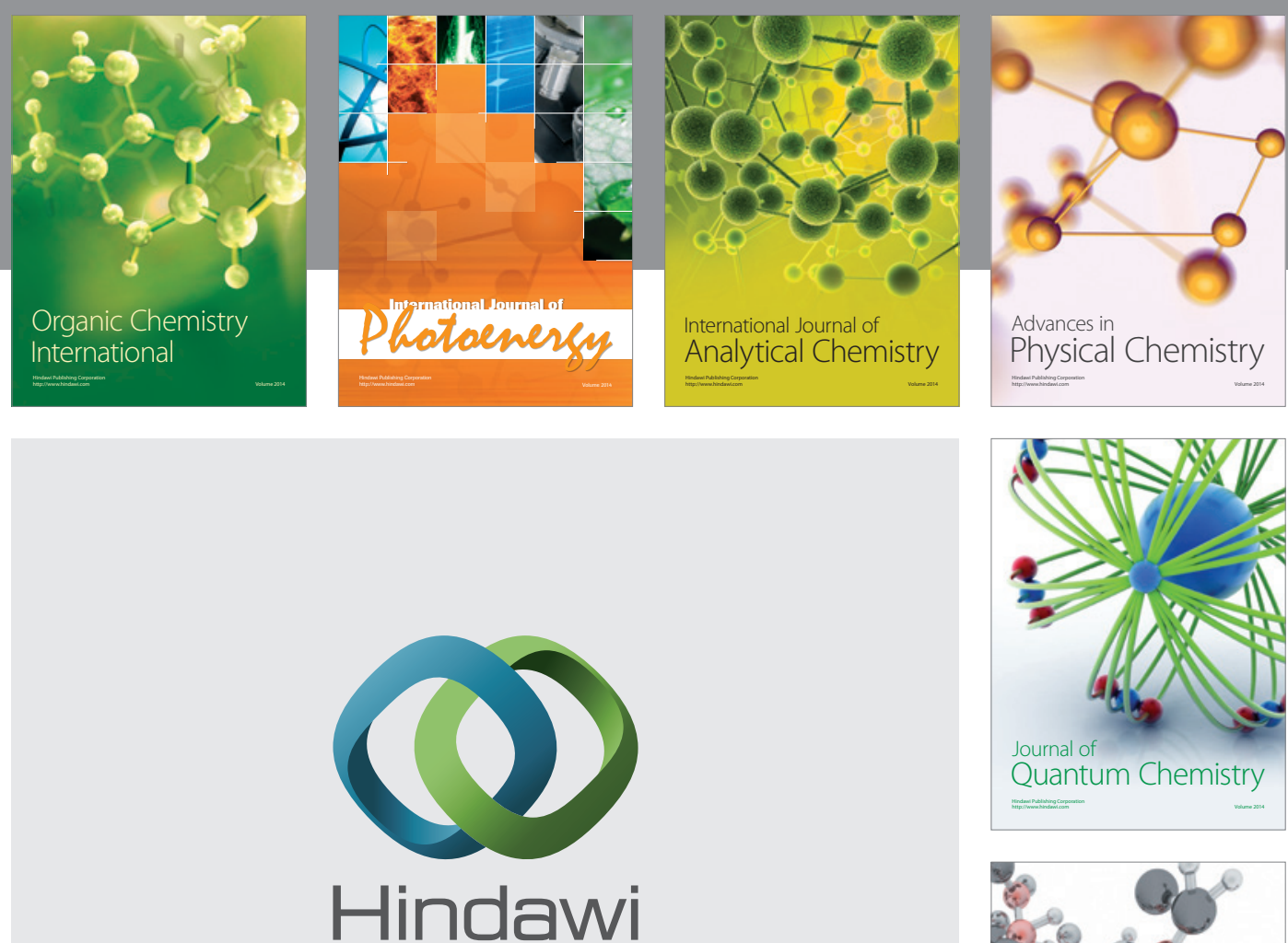

Submit your manuscripts at

http://www.hindawi.com

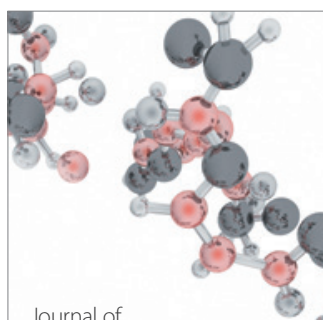

Analytical Methods

in Chemistry

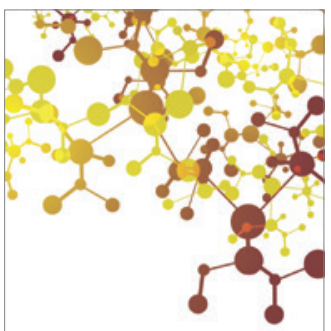

Journal of

Applied Chemistry

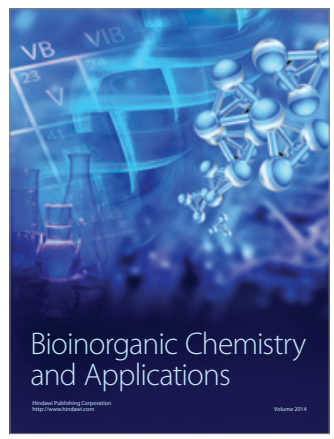

Inorganic Chemistry
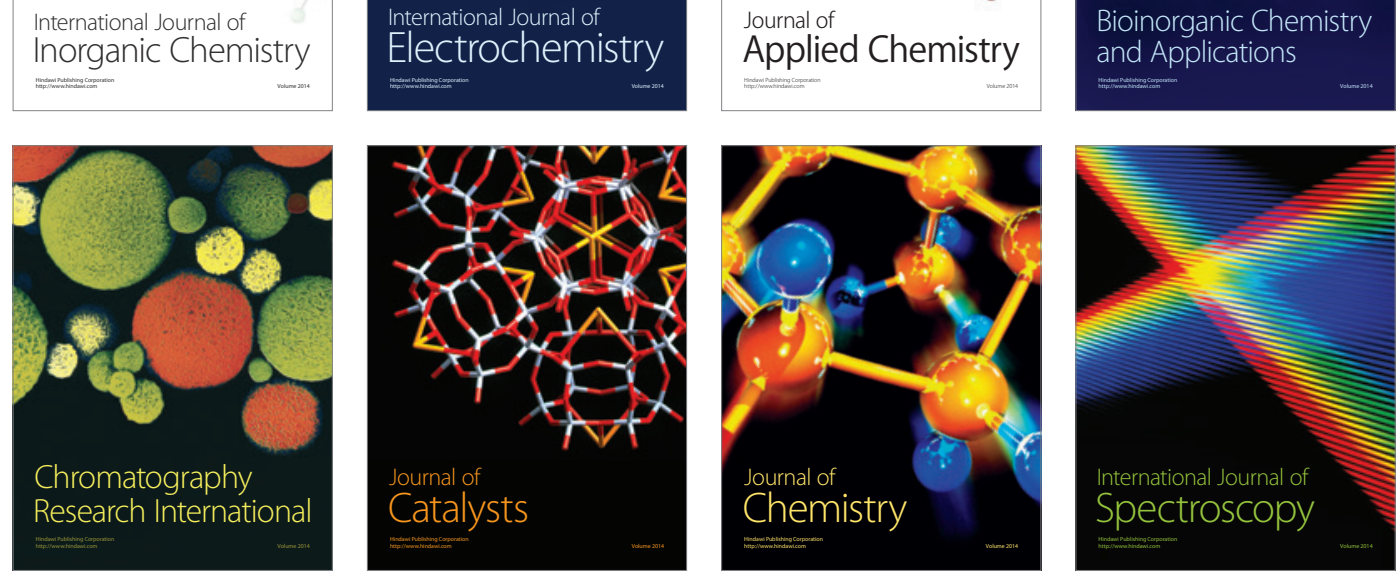